\title{
Wine Industry's Attitude towards Oenological Yeasts: Italy as a Case Study
}

\author{
Daniela Fracassetti ${ }^{1,+} \oplus$, Stefano Massaglia ${ }^{2,+} \oplus$, Andrea Viberti ${ }^{2}$, Giulia Motta ${ }^{1}$, \\ Roberto Foschino $^{2}$ (D) and Ileana Vigentini ${ }^{1, *}$ \\ 1 Department of Food, Environmental and Nutritional Sciences, Università degli Studi di Milano, \\ Via G. Celoria 2, 20133 Milan, Italy; daniela.fracassetti@unimi.it (D.F.); giulia.motta@gmail.com (G.M.) \\ 2 Department of Agricultural Forest and Food Sciences, Università degli Studi di Torino, Largo Braccini 2, \\ 10095 Grugliasco, Italy; stefano.massaglia@unito.it (S.M.); andrea.viberti@unito.it (A.V.); \\ roberto.foschino@unimi.it (R.F.) \\ * Correspondence: ileana.vigentini@unimi.it; Tel.: +39-0250-319-165; Fax: +39-0250-319-128 \\ + These authors contributed equally to this work.
}

Received: 26 March 2020; Accepted: 7 May 2020; Published: 17 May 2020

check for updates

\begin{abstract}
Yeast inoculation is a widespread practice in winemaking in order to control the must fermentation. However, the use of indigenous wine yeasts can enrich wine quality and differentiate wine styles. Yeast cream preparation (CRY), recently accepted by the International Organization of Vine and Wine, could allow an easier usage of autochthonous yeasts. This work aimed at investigating the actual Italian wine industry's attitude towards the available formulations of commercial wine yeasts with attention to CRY. Moreover, this study evaluated the perception of wineries toward indigenous yeasts in both winemaking and marketing viewpoints. Data show different levels of knowledge and use about the available yeast formulations. In general, there is not a predominantly positive or negative participants' opinion regarding the use of indigenous yeasts. Wineries using CRY ( $4 \%$ of the sample) mainly adopt them as a part of the production in order to compare the wines with the ones traditionally obtained with commercial yeasts. CRY is perceived by some interviewees as a potential tool to increase communication and product differentiation. This survey could have anticipated future trends in the use of yeast formulations, determined by the market demands for diversified, unique, and environmentally sustainable products, that can allow an accessible application of precision enology.
\end{abstract}

Keywords: commercial starter yeasts; autochthonous yeasts; cream yeasts; quality wine; precision oenology; wine marketing

\section{Introduction}

In winemaking, yeasts are essential for the transformation of grape sugars into ethanol and carbon dioxide through the alcoholic fermentation (AF) [1]. The principal yeast species involved in grape must fermentation is Saccharomyces cerevisiae and it comprises a very large number of strains which are selected and commercialized according to their different technological and sensory meaning in winemaking [2]. The inoculation of selected wine yeasts (Saccharomyces and non-Saccharomyces yeasts/local or imported) is a common practice in winemaking in order to improve the fermentation kinetics and leading to a predictable and desired quality in wine production, avoiding stuck or sluggish fermentations [3]. Furthermore, selected yeast strains constitute, in practice, an effective strategy for avoiding wine spoilage. Thus, winemakers are used to inoculate activated yeast starters which are managed to initiate and ensure completion of AF thanks to their high capability to cope with several environmental stresses [2-5]. 
An obvious consequence of the yeast inoculation practice is the standardization of sensory characteristics resulting from the fermentation process, including in quality wines, at the expense of the originality of aromas that could be expressed from the same products by exploiting indigenous micro-organisms [1,6]. In recent years, the exploitation of indigenous yeasts is a current topic in winemaking [7-11]. This trend supports safeguarding of the diversity of local products, and has a noteworthy impact in trade, especially by those consumers seeking typical foods. Nowadays, for a certain style of wines, the use of the so-called "indigenous (or autochthonous) yeasts" is considered essential in providing for the valorization and preservation of the environmental microbial biodiversity [6]. Indeed, it has been suggested that the land from which the grapes are grown imparts a unique quality to the wine, especially when spontaneous fermentations are carried out $[7,12]$. Thus, the wineries that employ indigenous yeasts promote the enhancement of biodiversity and the territorial microbiological heritage. While precision viticulture is currently applied to optimize the performance of vineyards in maximizing grape yield and quality [13], precision oenology could harness the technological potential of wild strains enhancing the flavor potential in local low aromatic cultivars and sealing the link between territory and final product [14]. Moreover, consumers show immense interest in the issues of sustainability and healthiness of food and beverages [15]. The increasing public attention to issues of health and environmental sustainability has contributed to a growing consumer demand for "natural" food and drinks, in fact this trend has also affected the wine market [16]. In recent years, several companies operating in the agri-food industry have incorporated the fundamental principles of environmental, economic, and social sustainability into their business models, in order to satisfy the purchasing decisions of wine buyers $[17,18]$.

A unique definition of the autochthonous yeast is still a controversial question among researchers: it is objectively assumed that a strain should originate in a site and persist in it for a certain period. The major issue is the determination of microbiota borders: it is not simple to place the boundary line in determining the membership of a strain on a territory. Should these boundaries include the walls of the cellar, the hill planted with the vines, or even the land in a valley or an island? How long does it take to consider a strain as a native micro-organism of that area? [7]. The microbiota of grapes varies according to climate (i.e., temperature, humidity), soil composition, and viticulture practices (i.e., fertilization, irrigation) [19]. Thus, the definition of indigenous yeast and in particular the location of its placement still remains an unresolved issue.

In response to a request from some producers to use indigenous yeast, several wine yeast companies have started offering assistance to wineries in producing autochthonous yeasts in Italy. These companies offer a service that includes the isolation of yeasts from grape, the identification of isolated yeasts, the technological characterization of yeasts, and the production of the starter strain. The isolation of yeasts from the grapes involves sampling in the vineyard and the subsequent isolation of yeasts in the laboratory. The species and strains of isolated yeasts are then identified using molecular techniques. Then follows the selection of high-performance strains and finally the preservation and production of the starter strain. The starter yeast is returned to the cellars as a cream yeast, ready for use. However, a shorter shelf-life of the product limits its commercialization in large territories; indeed, cream yeast cultures are usually provided by nearby industries sustaining the approach that should be applied to the indigenous yeasts. In 2017, the International Organization of Vine and Wine (OIV) recognized this tendency and included in the resolutions 576A-2017 and 576B-2017, presenting details about Saccharomyces and non-Saccharomyces yeasts' formulations, the Cream Yeast (CRY) preparation, with a range of dry matter from $18 \%$ to $25 \%$ and a level of viable yeasts equal to or above $10^{10} \mathrm{CFU} / \mathrm{g}$ of dry matter, together with Active Dry Yeast (ADY), Active Frozen Yeast (AFY), Compressed Yeast (COY), and Encapsulated (beads) or Immobilized Yeasts (ENY) [20].

This work aimed at investigating the actual wine industry's attitude towards the available formulations of commercial wine yeasts in Italy, with particular attention to the case of the CRY preparation in order to assess the knowledge, the use, and the potential acknowledgement of this formulation by cellars. CRY includes both autochthonous Saccharomyces and non-Saccharomyces yeasts, 
the latter forming a large part of the natural yeast flora on the grapes. Non-conventional yeasts have usually a lower fermentative power than Saccharomyces and are out competed by it, mainly due to their lower ethanol tolerance, but some species (excluding spoilage yeasts) can positively affect aroma compounds enriching the wine complexity [21]. At winemaking level, among the formulations approved by the OIV, CRY would allow an easier usage of autochthonous yeasts to conduct must fermentation. Indeed, after a massive biomass production, yeasts can be maintained as cream formulation and used for direct inoculation of grape must avoiding lyophilization, freeze- or spray-drying treatments that can negatively affect cell viability and the fermentative performance of the cells [22]. At market level, the use of indigenous yeasts could satisfy those consumers who are looking for "natural products" with a territorial link and respectful of the environmental biodiversity.

\section{Materials and Methods}

\subsection{Recruitment of Participants}

Data were collected from March 2019 until August 2019, using an online survey written in Italian created through Google Forms and hosted on the Google platform. The area covered by the questionnaire included Lombardy and Piedmont regions (North of Italy). In order to reach as many participants as possible, the wineries were contacted by a single e-mail. Approximately 400 wineries were sent a one-page invitation letter that stated the aim of the study and invited to complete an online questionnaire. The inclusion criteria required that participants needed to (1) be working in the winery as an oenotechnician/oenologist, winemaker, grape-grower, or winery owner and (2) be of 18 years or older to participate. To access the survey, a secure URL address was included in the letter. Identical questionnaires with different URL addresses were created for each production area in order to facilitate the final processing of the data. The estimated time to complete the questionnaire was about $5 \mathrm{~min}$ and the obligation to respond was inserted in some fields, which required a multiple-choice answer or an open answer.

\subsection{Variables Measured}

The survey consisted of three sections; the complete text is presented in Appendix A.

In the first section of the questionnaire, information about the winery (name and wine volumes), the interviewee (job role, age, and qualification), and the knowledge and use of yeast formulations in accordance with OIV-OENO 576A- 2017 and OIV-OENO 576B-2017 resolutions were requested. Each question in the first section required a mandatory answer. It was not necessary to enter the field of the production area as e-mails with different links were used depending on the consortia and the areas of the respondents. The field for "winery name" included an open answer, the "job role" and "qualification" included a multiple-choice answer, with the possibility to answer openly in "other", and the "age" field required only one multiple choice answer. The interviewees could choose among four different "job roles" and "positions": winery owner, employee, external consultant, and other. The "qualification" field included the choice between oenotechnician/oenologists and other. It was chosen to use both titles, because the title of oenologist was recognized through the Italian law n. 129 of 10 April 1991; previously at that date the winemaker in Italy had the title of oenotechnician. The field for the "average wine quantities" over the last 3 years had the following volume ranges: 500, 500-1000, 1000-2000, 2000-5000, 5000-10,000, 10,000-20,000, and over 20,000 hL. The choice to use hectoliters was made in accordance to both the target of the questionnaire and the measurement unit officially used by the OIV for the estimation of wine production. In the last field of the first section, concerning the knowledge and use of yeast formulations, respondents were required to give a mandatory answer for each of the five formulations considered (active dried yeast (ADY), active frozen yeast (AFY), compressed yeast (COY), cream yeast (CRY), encapsulated yeast (ENY)).

In the second section of the questionnaire, the opinion of the interviewees was requested based on six statements regarding the use of autochthonous yeasts. The definitions of indigenous 
(or autochthonous) yeast and selected yeast were reported at the beginning of this section, in order to clarify the meaning of these terms. The stated definitions were:

- Indigenous yeast: a yeast belonging to the natural microbiota of grapes able to initiate, lead, and complete the spontaneous fermentations of grape must;

- Selected yeast: a yeast guaranteeing a rapid start of fermentation and a quick inhibition of indigenous yeasts, as well as responding to specific technological and quality characteristics.

Six sentences were proposed including both winemaking (Get higher quality wines, Simplify the work in the cellar, Produce more natural wines, Use a yeast that permanently resides in a certain vineyard or in a certain cellar (terroir)) and marketing (Get more communication and product differentiation, Respond to market demands) aspects. The respondents assigned mandatory a score on a Likert scale from 1 (the interviewee did not agree at all with the sentence) to 5 (the interviewee agreed at all with the sentence). The main proposition was to understand the purpose why the wine producers choose native yeasts. At the end of the table there was the specific question: "Do you know the cream yeasts?" with a double-choice answer "Yes/No". In case of negative response, the questionnaire ended; in case of positive response, the third section was proposed to the respondents.

The third section of the questionnaire included questions allowing to better understand the diffusion of the CRY use for the winemaking. In particular, the origin of the knowledge and the reason for the use/not use/previous use of the CRY were requested. In both fields the obligation to reply was introduced. In addition, two closed-ended questions were related to the duration (for over 3 years, from 2-3 years, from 1 year, and from this year) of CRY use and the volumes of wine produced (total or partial production) with CRY inoculum. The CRY has recently been commercialized and it has been recognized by the OIV since 2017; for these reasons, time bands up to 3 years were reported. Finally, the specific type of winemaking was asked. In the latter three fields, the possibility of an answer was optional, since participants who were only familiar with CRY formulation could not respond to these last questions.

\subsection{Data Treatment and Analysis}

The results of the questionnaire were collected and processed through the Microsoft Excel program. From the Excel table containing the database questionnaire answers, Pivot tables were created in order to understand the interactions between fields of interest. Each column in the Excel table corresponds to a questionnaire field. The interpretation of the data was carried out through counting of values and for them the sum, the mean value, and the coefficient of variation were considered. In addition, Pivot tables allowed the filtering of specific area to display only fields of interest. A summary of the source was obtained in which data are structured and aggregated according to the relationships that are of greater interest. Once the data were grouped and statistically processed, graphs were created to highlight the interactions between the fields of the questionnaire. Further statistical analysis was done by SPSS software (SPSS Inc., Chicago, IL, USA). The correlation coefficients between the different yeast formulations and the reason for the use/not use/previous use of the CRY were computed through the Pearson correlation. Principal component analysis (PCA) was performed considering only the use of CRY considering the volume of wine produced, the age, the qualification, and the job position. Significant differences were assessed for $p<0.05$ by means of pair $t$-test. Partial least square (PLS) analysis was also carried out regarding use and knowledge of the yeast formulations considering the age and the position of participants. The variable importance in projection (VIP) scores were estimated in order to compare the importance of yeast formulations, age, and position of interviews.

\section{Results and Discussion}

\subsection{Description of Participants}

The questionnaire on the usage of yeasts in the winery was filled in 191 cellars of which $29 \%$ $(n=55)$ are located in Piedmont and the remaining $71 \%$ in Lombardy $(n=136)$. The total sample 
involved in the research included winery owners, employees, and external consultants representing $54 \%, 40 \%$, and $6 \%$, respectively. Considering the age, the majority of the participants resulted among: under 30 years (26\%), 31-40 years (26\%), and $41-50$ years $(23 \%)$ for a total of $75 \%$ of the interviewees; the remaining part included participants of $51-60$ years $(15 \%), 61-70$ years $(7 \%)$, and the over 70 years (3\%). In addition, data showed that the choice of yeast formulations was mainly managed by young people, who tend to be more up to date on new products on the market. Indeed, as the age group increases the number of participants decreases proportionally. A total of $68 \%$ of respondents were graduated; in particular, $62 \%$ of the participants had the title of oenotechnician/oenologists, $4 \%$ had a degree in Agricultural Sciences, 2\% received a degree not directly related to the agri-food field (e.g., Economics and Business), and 7\% had a high school diploma. A quarter of participants (25\%) did not specify the school qualification, but in the category "other" they defined themselves as winemaker, factotum, administrative employees, and wine lovers. The wineries participating in the research were mainly small-medium enterprises. In fact, most of the interviewees (38\%) produced less than $500 \mathrm{hL}$ of wine volumes over a period of 3 years. Only 11\% worked with volumes of higher than 20,000 hL. The other half of the participants (51\%) declared the production ranged from 500 to $10,000 \mathrm{hL}$ divided as follows: $19 \%$ of the interviewed produced $500-1000 \mathrm{hL}$ of wine, $10 \% 1000-2000 \mathrm{hL}, 12 \% 2000-5000 \mathrm{hL}$, 6\% 5000-10,000 hL, and 4\% 10,000-20,000 hL.

The interactions between the general data (age, education, qualification) were evaluated. The results showed that participants under 30 years of age ( $26 \%$ of the entire sample) were $90 \%$ oenotechnician/oenologists, 2\% had a degree in Agricultural Sciences, $4 \%$ had a high school diploma, and $4 \%$ belonged to the "other" category. Among the respondents in the age group 31-40 years of age ( $26 \%$ of the entire sample), $82 \%$ were oenotechnician/oenologists, $4 \%$ had a high school diploma, and $14 \%$ belonged to the "other" category. Participants between 41 and 50 years of age (23\% of the entire sample) were composed of $45 \%$ oenotechnician/oenologists, $7 \%$ had a degree in Agricultural Sciences, $7 \%$ had a degree in another subject, and 30\% belonged to the "other" category. Finally, of respondents over 51 (25\% of the entire sample), 27\% were oenotechnician/oenologists, $8 \%$ graduates in Agricultural Sciences, $2 \%$ graduates in another subject, $11 \%$ holders of a high school diploma, and 52\% belonged to the "other" category. As the age ranges decrease, the level of education increases. This relationship is probably due to a normal tendency for young students to continue their studies until the achievement of bachelor and/or master's degrees.

\subsection{The Use of Yeast Formulations}

The OIV has recognized different yeast formulations suitable for the wine production including ADY, AFY, COY, CRY, and ENY. The knowledge of the participants regarding the yeast formulations available and admitted is reported in Figure 1. A total of 191 cellars answered regarding the knowledge and use of ADY, 183 wineries for both AFY and COY, 186 cellars for CRY and ENY. As expected, the most well-known yeast formulation used by the interviewed wineries resulted ADY. Indeed, this kind of product is commercialized with success since 1879 when Christian Hansen's factory began producing a dried product for the dairy sector [23]. Only 2\% of wineries did not know this formulation and $79 \%$ claimed that they know and use it. AFY was unknown to $45 \%$ of participants and only $4 \%$ stated they use it. The least well-known formulation was the ENY, with $64 \%$ of participants not knowing it and only $1.5 \%$ declaring to use it. A total of $45 \%$ of participants were not familiar with CRY, although $8 \%$ said they had used it in the past and then abandoned it later; $4 \%$ of respondents continued to adopt it. Thirty-nine \% of the interviewees did not know the ENY formulation and only $2 \%$ used it to trigger the fermentation process (Figure 1).

Except for the ADY, the data collected for the other yeast formulations showed significant differences in terms of knowledge and use for the oenotechnicians/oenologists category. In this regard, for AFY, COY, ENY, and CRY, the category of oenotechnicians/oenologists was compared with the category including all other qualifications (i.e., Agricultural Sciences degree, other subject degree, high school diploma, other). Among oenotechnicians/oenologists, 20\% of them did not know AFY, 
while $18 \%$ of them knew it. Only $4 \%$ of oenotechnicians/oenologists currently use it, while it is not used by any of the other category participants. COY was the yeast formulation less known by the participants of the questionnaire (64\%). Surprisingly, this formulation was less known to oenotechnicians/oenologists (36\%) compared to those who do not have an enological qualification $(28 \%)$. Only $2 \%$ of oenotechnicians/oenologists stated that they are currently using this formulation. ENY was unknown to $16 \%$ of oenologists and to $23 \%$ of participants with another qualification. Only $2 \%$ of oenologists used it for fermentation processes, while almost none of the participants of "other qualification" currently use it. CRY was mainly known and used by the oenotechnicians/oenologists: $16 \%$ knew it, $18 \%$ admitted knowing it without ever having used it, $7 \%$ had abandoned it, and $4 \%$ currently use it. On the contrary, in the category of "other qualifications", this formulation was unknown to $28 \%$ of the participants and nobody currently uses it. This is probably due to the major contact of the oenotechnicians/oenologists with the yeast-producing companies and therefore they are immediately updated on the new products on the market.

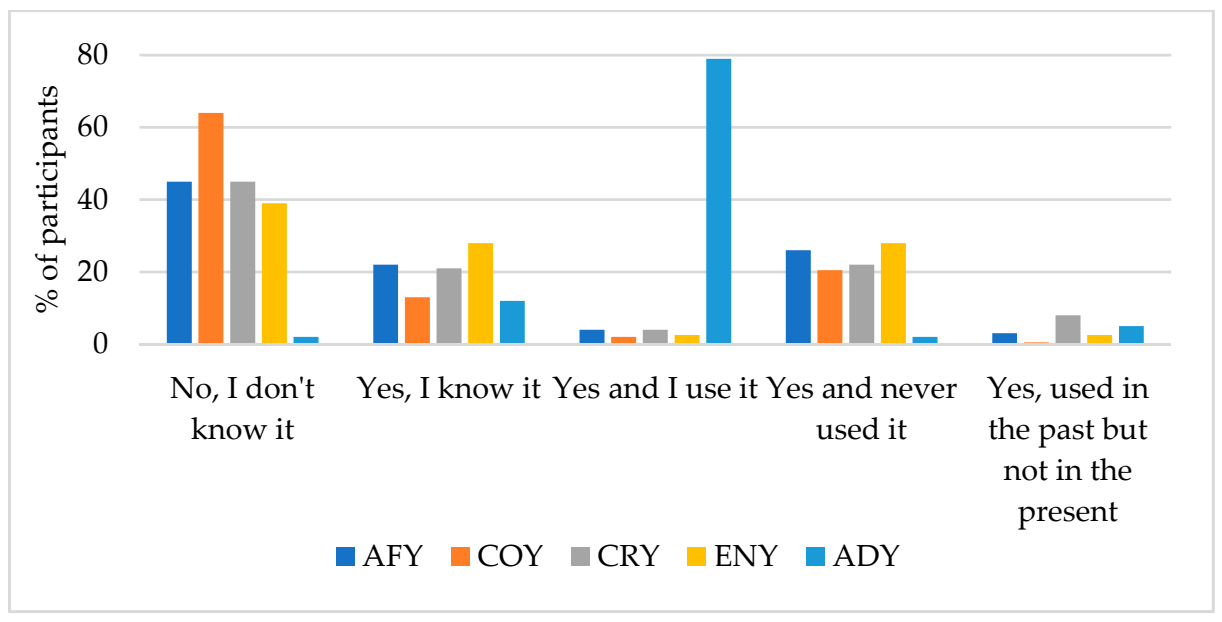

Figure 1. Knowledge and use of yeast formulations available for the winemaking and admitted by the International Organization of Vine and Wine. Legend: ADY, active dried yeast; AFY, active frozen yeast; COY, compressed yeast; CRY, cream yeast; ENY, encapsulated yeast.

A further confirmation of the diffusion of the different yeast formulations was revealed by the correlation indexes. In fact, ADY was negatively correlated with all the other yeast formulations, while AFY, COY, ENY, and CRY resulted positively correlated to each other (Table 1). These data indicate the high use of ADY that is the predominant yeast formulation diffused in the wine industry in comparison to the other yeast formulations admitted; AFY, COY, ENY, and CRY are only barely employed in a comparable way even because high and positive correlation indexes were found among them $(>0.8)$.

Table 1. Correlation indexes among the yeast formulations available for the winemaking and admitted by the International Organization of Vine and Wine.

\begin{tabular}{cccccc}
\hline Yeast Formulations & AFY & COY & CRY & ENY & ADY \\
\hline AFY & 1.000 & 0.947 & 0.984 & 0.967 & -0.546 \\
COY & & 1.000 & 0.971 & 0.837 & -0.439 \\
CRY & & & 1.000 & 0.929 & -0.590 \\
ENY & & & & 1.000 & -0.598 \\
ADY & & & & & 1.000 \\
\hline
\end{tabular}

Legend: ADY, active dried yeast; AFY, active frozen yeast; COY, compressed yeast; CRY, cream yeast; ENY, encapsulated yeast. 
Partial least square analysis (PLS) was performed with the purpose of understanding the influence of age, position, and use of the different yeast formulations considering variable importance of projection (VIP) scores. Four components were found explaining 41\% of the variance; in particular, P1, P2, and P3 resulted significant explaining 15\% of variance for seven interactions, $14 \%$ of variance for six interactions, and $15 \%$ of variance for eight interactions, respectively, for P1, P2, and P3. P4 was not significant and it explained $14 \%$ of variance. It is interesting to note the variable most important was ADY when considering both yeast formulations/age and yeast formulations/age/position (Table 2). Age ( $\leq 30$ years) showed a higher influence among the age ranges considered and major importance scores were found for consultant, owner, and employee when the position was also considered. This suggests a link exists between the choices concerning the winemaking process, specifically the use of certain yeast formulation, and younger individuals dealing with the wine production with greater decisions depending on consultants and owners.

Table 2. Variable importance projection (VIP) scores obtained by the partial least square analysis.

\begin{tabular}{|c|c|c|c|}
\hline & Variable & VIP & Importance \\
\hline \multirow{11}{*}{ Yeast formulation/Age } & Yeast formulation (ADY) & 2.240 & 1 \\
\hline & Age $(\leq 30$ years $)$ & 1.264 & 2 \\
\hline & Age (>70 years) & 1.007 & 3 \\
\hline & Age (61-70 years) & 0.955 & 4 \\
\hline & Yeast formulation (COY) & 0.918 & 5 \\
\hline & Age (31-40 years) & 0.687 & 6 \\
\hline & Yeast formulation (ENY) & 0.679 & 7 \\
\hline & Yeast formulation (AFY) & 0.560 & 8 \\
\hline & Yeast formulation (CRY) & 0.443 & 9 \\
\hline & Age (51-60 years) & 0.389 & 10 \\
\hline & Age (41-50 years) & 0.152 & 11 \\
\hline \multirow{15}{*}{ Yeast formulation/Age/Position } & Yeast formulation (ADY) & 1.770 & 1 \\
\hline & Position (Consultant) & 1.669 & 2 \\
\hline & Position (Owner) & 1.519 & 3 \\
\hline & Position (Employee) & 1.241 & 4 \\
\hline & Age $(\leq 30$ years $)$ & 0.975 & 5 \\
\hline & Position (Oenologist) & 0.905 & 6 \\
\hline & Yeast formulation (COY) & 0.831 & 7 \\
\hline & Age $(>70$ years $)$ & 0.805 & 8 \\
\hline & Age (61-70 years) & 0.746 & 9 \\
\hline & Yeast formulation (CRY) & 0.655 & 10 \\
\hline & Yeast formulation (ENY) & 0.625 & 11 \\
\hline & Age (31-40 years) & 0.542 & 12 \\
\hline & Age (51-60 years) & 0.460 & 13 \\
\hline & Yeast formulation (AFY) & 0.460 & 14 \\
\hline & Age (41-50 years) & 0.178 & 15 \\
\hline
\end{tabular}

\subsection{Indigenous Yeast or Selected Yeast: This is the Question}

The oenological practice to perform the inoculum starter yeast strain(s) ensuring the alcoholic fermentation to be concluded is usually carried out by several wineries. However, spontaneous fermentations, conducted by different Saccharomyces and non-Saccharomyces yeasts, are getting increasing interest, at biotechnological level as well, in order to preserve the terroir characteristics and differentiate the wine style in terms of aroma complexity [24].

Data regarding the use of indigenous yeasts in wine industry (including both winemaking and marketing aspects) showed that there were few significant differences regarding the participants' opinion to the sentences in the questionnaire. In particular, the highest mean values $(>3)$ were found for "Get more communication and product differentiation" (mean value: 3.42), "Use a yeast that permanently resides in a certain vineyard or in a certain cellar (terroir)" (mean value: 3.15), and "Get 
higher quality wines" and "Respond to market demands" (mean value: 3.07) (Table 3). These sentences belonged to both winemaking and marketing parts indicating the great importance of both aspects for the wine industry. The mean values that had the lowest mean value was "Produce more natural wines" (2.63).

Table 3. Mean values and coefficients of variation related to the use of indigenous yeast.

\begin{tabular}{|c|c|c|c|}
\hline \multicolumn{2}{|c|}{ The Use of Native Yeasts Can be Used by Producers in Order to } & \multirow{2}{*}{$\frac{\text { Mean Value }}{3.07}$} & \multirow{2}{*}{$\frac{\text { Coefficient of Variation }}{1.22}$} \\
\hline \multirow{4}{*}{ Winemaking } & Get higher quality wines & & \\
\hline & Simplify the work in the cellar & 2.84 & 1.31 \\
\hline & Produce more natural wines & 2.63 & 1.16 \\
\hline & $\begin{array}{l}\text { Use a yeast that permanently resides in a } \\
\text { certain vineyard or in a certain cellar (terroir) }\end{array}$ & 3.15 & 1.13 \\
\hline \multirow[t]{2}{*}{ Marketing } & $\begin{array}{l}\text { Get more communication and product } \\
\text { differentiation }\end{array}$ & 3.42 & 1.07 \\
\hline & Respond to market demands & 2.91 & 1.09 \\
\hline
\end{tabular}

The lowest and highest values are in bold.

The two extremes represented marketing and winemaking parts for the highest and lowest mean values, respectively. Therefore, the interactions between the answers of these two sentences and different fields of the questionnaire were therefore evaluated.

The sentence relating to the possibility of using autochthonous yeasts to produce more natural wines did not find the agreement of oenologists (mean value: 2.44). Furthermore, the coefficient of variation is very low, and it means that oenotechnicians/oenologists mostly have the same opinion on the sentence. Participants with a different qualification expressed a moderate disagreement regarding this statement (mean value: 2.93). Regarding the possibility of obtaining greater productive communication with the use of autochthonous yeasts, oenotechnicians/oenologists were very much in agreement with this sentence (average value: 3.47). However, participants with other qualifications were in agreement with the content of the sentence (average value: 3.34). This result shows that the necessities linked to marketing are perceived even by people with multiple qualifications, unlike the needs of winemaking (Table 3).

Both the over and the under 40 years did not agree on the use of autochthonous yeasts to obtain more natural wines. In particular, the under-40s showed greater disagreement (mean value: 2.46) with respect to the older class (2.80). Instead, with the phrase concerning the use of indigenous yeasts to obtain a greater differentiation of the product, both age groups were in agreement on the same opinion, that is the autochthonous yeast could be an optimal instrument of productive communication. (Table 4).

Table 4. Mean values and coefficients of variation related to the interactions between use of indigenous yeast for the two statements having the lowest (Produce more natural wines) and highest (Get more communication and product differentiation) mean values, and qualification (oenotechnicians/oenologists; other) and age ( $>40$ years old; $\leq 40$ years old).

\begin{tabular}{cccc}
\hline Statement & Subsample Characteristic & Mean Value & Coefficient of Variation \\
\hline & Oenotechnician/Oenologists & 2.44 & 0.98 \\
Produce more natural & Other & 2.93 & 1.36 \\
wines 1 & $>40$ years old & 2.80 & 1.23 \\
& $\leq 40$ years old & 2.46 & 1.07 \\
Get more & Oenotechnician/Oenologists & 3.47 & 1.02 \\
communication and & Other & 3.34 & 1.16 \\
product differentiation ${ }^{2}$ & $>40$ years old & 3.29 & 1.15 \\
& $\leq 40$ years old & 3.54 & 0.98 \\
\hline
\end{tabular}

${ }^{1}$ Mean value: $2.63 .{ }^{2}$ Mean value: 3.42 .

The correlation indexes among the statements describing the reasons why certain yeast formulation is used for the winemaking was calculated (Table 5). The results showed that the two aspects having 
major impact for the choice of indigenous yeast are related to the winemaking: "Use a yeast permanently residing in a certain terroir" and "Get higher quality wines" $(r=0.960)$. The latter was also highly correlated to "Respond to market demands" ( $r=0.955)$ indicating the strong attention on production of quality wine as a consumers' request. The fundamental role of consumer-related choices was found for the respect of the terroir $(r=0.927)$ that affects the expectation of specific wine characteristics. The lowest correlation values were determined among "Get more communication and product" and "Produce more natural wines" $(r=0.090)$ and "Simplify the work in the cellar" $(r=0.099)$. These findings indicate the negligible influence of the communication strategies in terms of production of natural wine. However, the production of more natural wine seems to make easier the winemaking management as high positive correlation was found with "Simplify the work in the cellar" (Table 5).

Table 5. Correlation indexes among the statements related to the use of indigenous yeast.

\begin{tabular}{|c|c|c|c|c|c|c|c|}
\hline & \multirow[b]{2}{*}{ Statement } & \multicolumn{4}{|c|}{ Winemaking } & \multicolumn{2}{|c|}{ Marketing } \\
\hline & & $\begin{array}{l}\text { Get } \\
\text { Higher } \\
\text { Quality } \\
\text { Wines }\end{array}$ & $\begin{array}{l}\text { Simplify } \\
\text { the Work } \\
\text { in the } \\
\text { Cellar }\end{array}$ & $\begin{array}{l}\text { Produce } \\
\text { More } \\
\text { Natural } \\
\text { Wines }\end{array}$ & $\begin{array}{l}\text { Use a Yeast } \\
\text { Permanently } \\
\text { Residing in a } \\
\text { Certain } \\
\text { Terroir }\end{array}$ & $\begin{array}{c}\text { Get More } \\
\text { Communication } \\
\text { and Product } \\
\text { Differentiation }\end{array}$ & $\begin{array}{l}\text { Respond } \\
\text { to Market } \\
\text { Demands }\end{array}$ \\
\hline \multirow{5}{*}{ 㫄 } & $\begin{array}{l}\text { Get Higher } \\
\text { Quality Wines } \\
\text { Simplify the }\end{array}$ & 1.000 & 0.598 & 0.674 & 0.960 & 0.710 & 0.955 \\
\hline & $\begin{array}{c}\text { Work in the } \\
\text { Cellar }\end{array}$ & & 1.000 & 0.873 & 0.401 & 0.099 & 0.695 \\
\hline & $\begin{array}{c}\text { Produce More } \\
\text { Natural Wines } \\
\text { Use a Yeast }\end{array}$ & & & 1.000 & 0.574 & 0.090 & 0.831 \\
\hline & $\begin{array}{l}\text { Permanently } \\
\text { Residing in a }\end{array}$ & & & & 1.000 & 0.789 & 0.927 \\
\hline & Certain Terroir & & & & & & \\
\hline \multirow{6}{*}{ 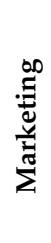 } & Get More & & & & & & \\
\hline & $\begin{array}{l}\text { Communication } \\
\text { and Product }\end{array}$ & & & & & 1.000 & 0.604 \\
\hline & Differentiation & & & & & & \\
\hline & Respond to & & & & & & \\
\hline & Market & & & & & & 1.000 \\
\hline & Demands & & & & & & \\
\hline
\end{tabular}

The lowest and highest values are in bold.

The perception of the wineries on the use of autochthonous yeasts regards the production of quality wine in which the terroir characteristics are preserved and as a procedure to effectively respond to the consumers' demands and expectations.

Particular attention was given to the use of CRY since it represents an emerging yeast formulation recently allowed by OIV that can make a bridge among the winemaking and marketing aspects mentioned above.

\subsection{The Cream Yeast: Formulation for the Future?}

More information about the knowledge of CRY was asked of the participants. Regarding the channel of knowledge ("How did you learn about CRY?"), 35\% of respondents knew CRY thanks to selling companies, $14 \%$ through the university, $14 \%$ belonged to the "other" category, $13 \%$ thanks to work experience, $9 \%$ from sector articles, $8 \%$ thanks to colleagues, and $7 \%$ through conventions (Figure 2a). 


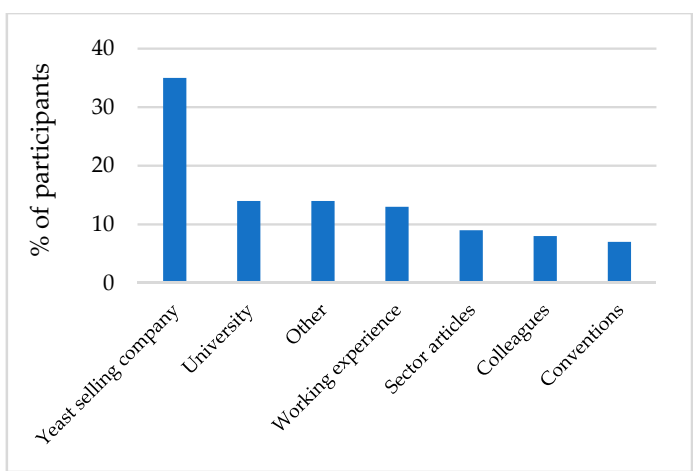

(a)

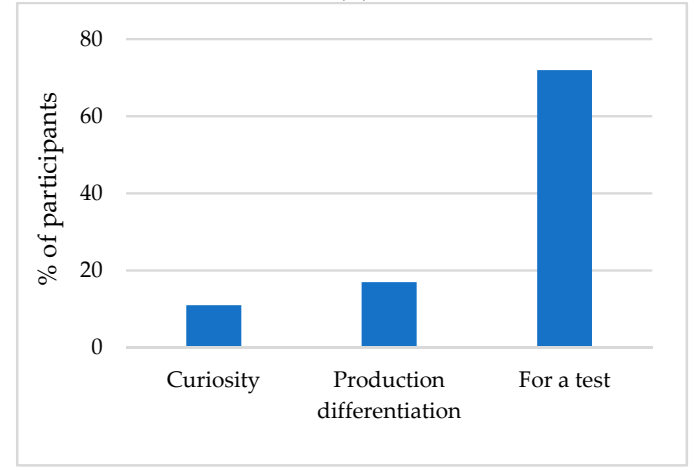

(c)

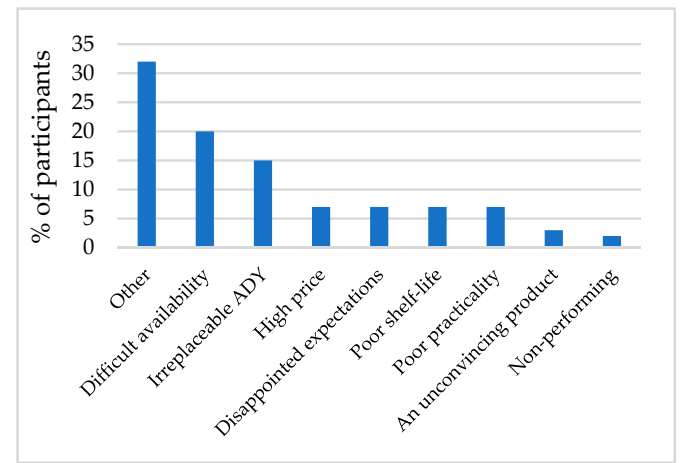

(b)

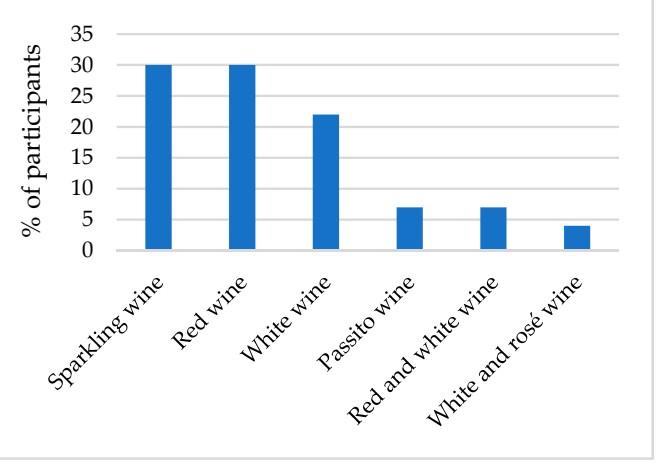

(d)

Figure 2. Knowledge and use of cream yeast (CRY). (a) channel of knowledge; (b) reason for using/not using CRY; (c) reason of use; (d) winemaking process in which CRY has been used.

Then interviewees were asked the reason for using/not using CRY. Participants who did not use CRY underlined the following problems: difficult availability (20\%), irreplaceable ADY (15\%), high price $(7 \%)$, disappointed expectations $(7 \%)$, poor shelf-life $(7 \%)$, poor practicality $(7 \%)$, poor product conviction (3\%), and non-performing formulation (2\%) (Figure $2 \mathrm{~b}$ ). As 32\% of participants did not express their own opinion, maybe this choice is due to a company policy or to the lack of the product knowledge. Participants who used CRY explained that they ran a test $(72 \%)$, used it for a production differentiation (17\%), and were curious about the new product on the market (11\%) (Figure 2c). Most of the participants used the CRY for a test, probably because they do not fully trust a product that has recently appeared on the market and they would understand the influence of CRY on the overall wine characteristics.

A total of $46 \%$ of the participants in the questionnaire adopted CRY in 2018. In particular, $25 \%$ of them have used it for a year, $14 \%$ for $2-3$ years, and $20 \%$ for more than 3 years. From the data it is possible to observe that the adoption of CRY is an extremely current choice.

However, only $4 \%$ of respondents have already adopted CRY for the vinification of all production volumes. Instead most of the interviewees $(96 \%)$ have used it only on part of the production, probably to carry out experimental tests and evaluate the advantages and disadvantages of this emerging yeast formulation. According to the data, CRY has been inoculated to obtain the following types of wines: sparkling wine $(30 \%)$, red wine $(30 \%)$, white wine $(22 \%)$, passito wine $(7 \%)$, both red and white wine $(7 \%)$, and both white and rosé wine (4\%) (Figure 2d).

The interactions between the general data (age, education, qualification), the use of CRY, the volume of wine produced was evaluated by means of the principal component analysis (PCA). Four components were found explaining 38\% of the variance; in particular, P1 was significant and it explained $14 \%$ of the variance. The significance of both P2 and P3 was unknown and they explained $10 \%$ and $7 \%$ of variance, respectively, for P2 and P3. P4 was not significant and it explained $7 \%$ of the variance. The results showed the oenotechnicians/oenologists were more involved with the use of CRY for those being less than 40 years old in case of employees in particular. CRY did not result in use for wine 
production lower than $500 \mathrm{hL}$, while it was used even in the wineries where more than 20,000 hL of wine is produced (Figure 3). This could be due to the major contacts of bigger wineries to yeast selling companies as well as to the possibility for them of performing tests or modifying existing winemaking procedures but still maintaining the traditional ones. The above-mentioned findings were highlighted by comparing P1 (significant) with both P2 (Figure 3a) and P3 (Figure 3b) (unknown significance). In both cases, the major characteristics related to the use of CRY are oenotechnicians/oenologists as qualification, less than 40 years old, employees as position, and high volume of wine produced (more than $2000 \mathrm{hL}$ ). On the contrary, the main outcomes of PCA showed small production volumes (lower than $500 \mathrm{hL}$ ), "other" qualification, and age range 40-60 years old regarded the use of yeast formulations other than CRY.

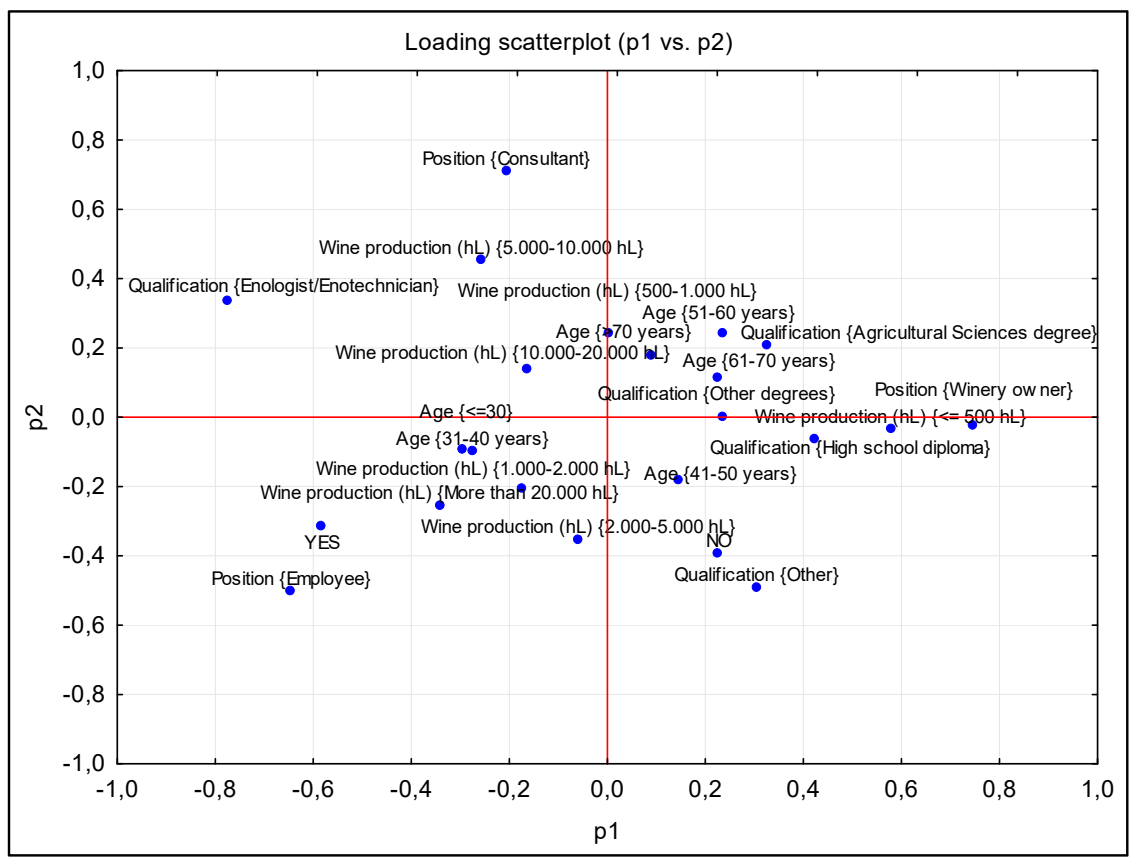

(a)

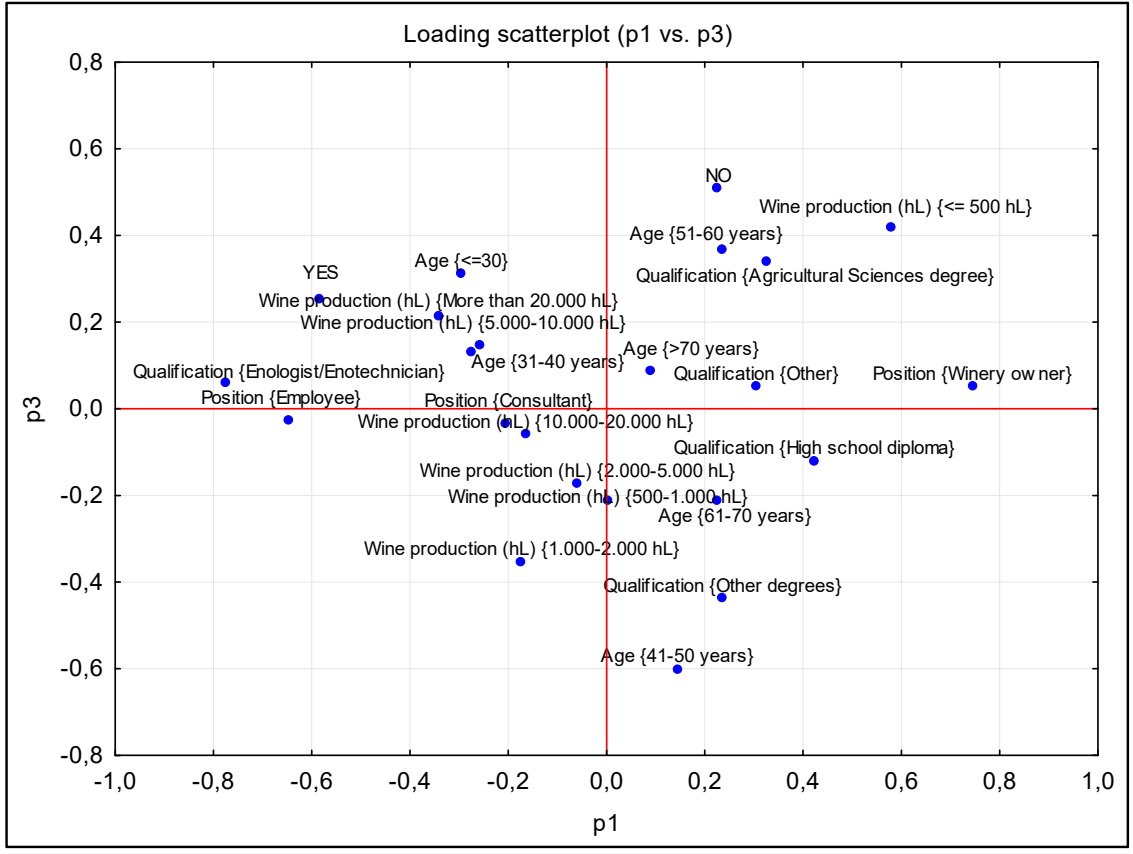

(b)

Figure 3. Loading scatterplot (a) P1 vs. P2 and (b) P1 vs. P3. 
A further confirmation of the major role played by employees with qualification of oenotechnician/oenologists was demonstrated by the higher power shown in the PCA matrix. The winery owner also influenced the choice of using CRY, but with lower strength in comparison to the employee (Table 6).

Table 6. Variable importance obtained by the principal component analysis.

\begin{tabular}{ccc}
\hline Variable & Power & Importance \\
\hline Qualification (Oenotechnician/Oenologists) & 0.773 & 1 \\
Position (Employee) & 0.753 & 2 \\
Position (Winery owner) & 0.687 & 3 \\
Position (Consultant) & 0.562 & 4 \\
Qualification (Other) & 0.538 & 5 \\
Wine production (hL) ( $\leq 500 \mathrm{hL})$ & 0.527 & 6 \\
Age (41-50 years) & 0.447 & 7 \\
Age (51-60 years) & 0.416 & 8 \\
Wine production (hL) (More than 20,000 hL) & 0.357 & 9 \\
Wine production (hL) (5000-10,000 hL) & 0.317 & 10 \\
Qualification (Other degrees) & 0.286 & 11 \\
Qualification (Agricultural Sciences degree) & 0.285 & 12 \\
Wine production (hL) (500-1000 hL) & 0.243 & 13 \\
Age (31-40 years) & 0.242 & 14 \\
Wine production (hL) (1000-2000 hL) & 0.236 & 15 \\
Wine production (hL) (2000-5000 hL) & 0.232 & 16 \\
Qualification (High school diploma) & 0.227 & 17 \\
Age ( $\leq 30$ years) & 0.217 & 18 \\
Wine production (hL) (10,000-20,000 hL) & 0.161 & 19 \\
Age (61-70 years) & 0.136 & 20 \\
Age ( $>70$ years) & 0.062 & 21 \\
\hline
\end{tabular}

\section{Conclusions}

In conclusion, the collected data show different levels of knowledge and use about the yeast formulations recognized by OIV. As expected, ADY formulation was the most consolidated product among the wineries of the sample. It is widely known not only by experts of wine sector (oenologists), but also by those persons who have a different qualification. The other yeast formulations are in general little known by the sample. Oenotechnicians and oenologists seem to be more prepared on the knowledge and use of formulations approved by OIV, even though some are still spread little in the wine world (e.g., COY). Data from the second section shows that there is not a predominantly positive or negative participants' opinion regarding the sentences about "autochthonous yeasts". However, the interviewees show disagreement about the possibility of using autochthonous yeasts in order to obtain more "natural wines". While they agree on the possibility of using indigenous yeasts to obtain greater communication and productive differentiation.

Regarding CRY, the oenotechnicians/oenologists category is the one most informed about this formulation, but only a minority had the opportunity to use it. Furthermore, although yeast selling companies are promoting the use of this new formulation, CRY is still little known by many cellars. Wineries that use CRY ( $4 \%$ of the sample) mainly adopt it on a part of the production to make a comparison between the wine obtained with this formulation and one produced with other yeast formulations. Moreover, some interviewees are not interested by a new formulation, indicating a partial closure toward innovative approaches, but recognize in cream yeast a potential tool to increase communication and product differentiation.

This survey certainly allowed us to evaluate the most used and known formulations and could have anticipated future trends in the use of yeast formulations, determined by the market demands for diversified, unique, and environmentally sustainable products. CRY formulation would result in the application of precision enology to support and confirm the link between the territory and the wine. 
Author Contributions: Conceptualization, I.V., S.M.; methodology, I.V., D.F. and S.M.; software, A.V.; validation, D.F. and G.M.; formal analysis, S.M.; investigation, D.F. and S.M.; resources, R.F., G.M. and A.V.; data curation, I.V.; writing-original draft preparation, I.V. and D.F.; writing—review and editing, I.V., D.F., S.M. and R.F.; supervision, I.V.; funding acquisition, D.F. and I.V. All authors have read and agreed to the published version of the manuscript.

Funding: The study was supported by Piano di Sostegno alla Ricerca 2019—Linea 2-Università degli Studi di Milano.

Acknowledgments: The authors acknowledge all the participants of the questionnaire.

Conflicts of Interest: The authors declare no conflict of interest.

\section{Appendix A. Questionnaire}

\section{FIRST SECTION}

${ }^{*}$ Required field

1. Information about the interview:

- Company/cellar*:

- Role*:

Cellar owner

口 Employee

External consultant

$\square$ Other:

- Age*:

$$
\begin{array}{ll}
\square & \leq 30 \text { years old } \\
\square & 31-40 \text { years old } \\
\square & 41-50 \text { years old } \\
\square & 51-60 \text { years old } \\
\square & 61-70 \text { years old } \\
\square & \geq 70 \text { years old }
\end{array}
$$

- Qualification*:

Enologist/ enotechnician

$\square$ Other:

2. Average production volume in the last three years*

$$
\begin{array}{ll}
\square & \leq 500 \mathrm{hL} \\
\square & 500-1000 \mathrm{hL} \\
\square & 1000-2000 \mathrm{hL} \\
\square & 2000-5000 \mathrm{hL} \\
\square & 5000-10,000 \mathrm{hL} \\
\square & 10,000-20,000 \mathrm{hL} \\
\square & >20,000 \mathrm{hL}
\end{array}
$$

3. In accordance with OIV-OENO 576A-2017 and OIV-OENO 576B-2017 Resolutions, the selected Saccharomyces and non-Saccharomyces yeasts used for the inoculation of grapes, musts and wines are commercialized in the formulations reported in the following table. Which ones do you know and/or use? (Please select only one reply for each formulation) * 


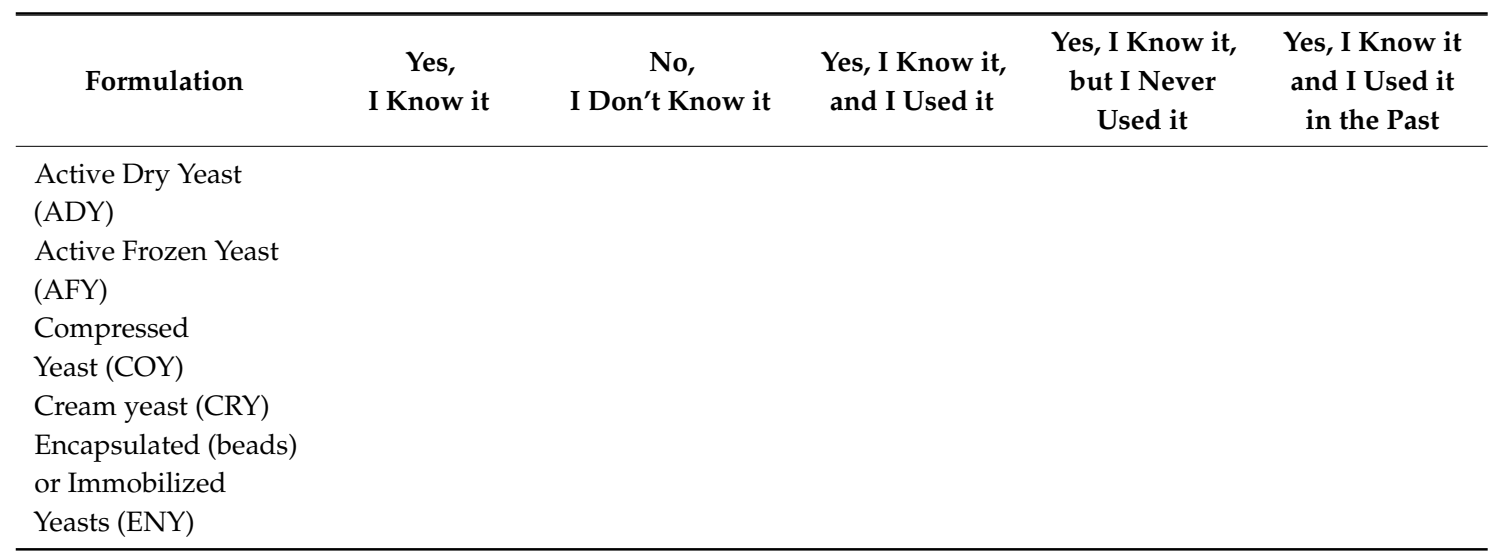

\section{SECOND SECTION}

*Required field

Based on the following definitions of indigenous (or autochthonous) yeast and selected yeast:

- Indigenous (or autochthonous) yeast: yeast belonging to the natural microflora of grapes able to initiate, to lead and to complete the spontaneous fermentations of grape musts

- Selected yeast: yeast that can guarantee a rapid start of fermentation and a quick inhibition of indigenous yeasts, as well as responding to specific technological and quality characteristics.

How much do you agree with the following statements? Indicate a score between 1 (strongly disagree) to 5 (strongly agree) *.

The use of autochthonous yeasts can be helpful for the producers to:

\begin{tabular}{|c|c|c|c|c|c|}
\hline & $\begin{array}{c}\text { Strongly } \\
\text { Disagree (1) }\end{array}$ & $\begin{array}{c}\text { Somewhat } \\
\text { Disagree (2) }\end{array}$ & $\begin{array}{c}\text { Neither Agree } \\
\text { nor Disagree (3) }\end{array}$ & $\begin{array}{c}\text { Somewhat } \\
\text { Agree (4) }\end{array}$ & $\begin{array}{l}\text { Strongly } \\
\text { Agree (5) }\end{array}$ \\
\hline \multicolumn{6}{|l|}{$\begin{array}{l}\text { Produce wine with } \\
\text { major quality }\end{array}$} \\
\hline \multicolumn{6}{|l|}{$\begin{array}{l}\text { Make easier the work } \\
\text { in the cellar }\end{array}$} \\
\hline \multicolumn{6}{|l|}{ Produce natural wine } \\
\hline \multicolumn{6}{|l|}{ Use a yeast that } \\
\hline \multicolumn{6}{|l|}{ permanently resides } \\
\hline \multicolumn{6}{|l|}{ in a certain vineyard } \\
\hline \multicolumn{6}{|l|}{ or cellar (terroir) } \\
\hline \multicolumn{6}{|l|}{ Obtain greater } \\
\hline \multicolumn{6}{|l|}{ communication and } \\
\hline \multicolumn{6}{|l|}{ product } \\
\hline \multicolumn{6}{|l|}{ differentiation } \\
\hline \multicolumn{6}{|l|}{ Answer the market } \\
\hline demands & & & & & \\
\hline
\end{tabular}

Do you know the cream yeast? *

Yes $\square$ No

THIRD SECTION (reserved to participants using cream yeasts)

${ }^{*}$ Required field

a. How did you know the cream yeast? *

b. Why do you use it/do not you use it/you use it no? *

c. If you use the cream yeast, for how long? 


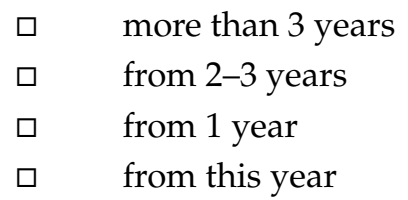

d. On which part of the wine production did/do you use the cream yeast?

$\square \quad$ On the entire production

$\square \quad$ On a part of the production (please specify in the next paragraph the wine(s) produced with cream yeast):

e. Indicate the wine production(s) carried out with yeast cream.

\section{References}

1. Romano, P. Function of yeast species and strains in wine flavour. Int. J. Food Microbiol. 2003, 86, 169-180. [CrossRef]

2. Ribérau-Gayon, P.; Dubourdieu, D.; Donèche, B.; Lonvaud, A. Handbook of Enology: The Microbiology of Wine and Vinifications, 2nd ed.; John Wiley and Sons: Hoboken, NJ, USA, 2006; Volume 1, pp. 22-35, ISBN 0-470-01034-7.

3. De Celis, M.; Ruiz, J.; Martín-Santamaría, M.; Alonso, A.; Marquina, D.; Navascués, E.; Gómez-Flechoso, M.Á.; Belda, I.; Santos, A. Diversity of Saccharomyces cerevisiae yeasts associated to spontaneous and inoculated fermenting grapes from Spanish vineyards. Lett. Appl. Microbiol. 2019, 68, 580-588. [CrossRef] [PubMed]

4. Comitini, F.; Capece, A.; Ciani, M.; Romano, P. New insights on the use of wine yeasts. Curr. Opin. Food Sci. 2017, 13, 44-49. [CrossRef]

5. Gélinas, P. Active Dry Yeast: Lessons from Patents and Science. Compr. Rev. Food Sci. Food Saf. 2019, 18, 1227-1255. [CrossRef]

6. Pretorius, I.S. Tailoring wine yeast for the new millennium: Novel approaches to the ancient art of winemaking. Yeast 2000, 16, 675-729. [CrossRef]

7. Di Maio, S.; Polizzotto, G.; Di Gangi, E.; Foresta, G.; Genna, G.; Verzera, A.; Scacco, A.; Amore, G.; Oliva, D. Biodiversity of indigenous Saccharomyces populations from old wineries of southeastern Sicily (Italy): Preservation and economic potential. PLoS ONE 2012, 7, e30428. [CrossRef]

8. Settanni, L.; Sannino, C.; Francesca, N.; Guarcello, R.; Moschetti, G. Yeast ecology of vineyards within Marsala wine area (western Sicily) in two consecutive vintages and selection of autochthonous Saccharomyces cerevisiae strains. J. Biosci. Bioeng. 2012, 114, 606-614. [CrossRef] [PubMed]

9. Vigentini, I.; Fracassetti, D.; Picozzi, C.; Foschino, R. Polymorphisms of Saccharomyces cerevisiae Genes Involved in Wine Production. Curr. Microbiol. 2009, 58, 211-218. [CrossRef] [PubMed]

10. Vigentini, I.; De Lorenzis, G.; Fabrizio, V.; Valdetara, F.; Faccincani, M.; Panont, C.A.; Picozzi, C.; Imazio, S.; Failla, O.; Foschino, R. The vintage effect overcomes the terroir effect: A three-year survey on the wine yeast biodiversity in Franciacorta and Oltrepò Pavese, two northern Italian vine-growing areas. Microbiology 2015, 161, 362-373. [CrossRef] [PubMed]

11. Available online: https://www.mdpi.com/journal/fermentation/special_issues/non-saccharomyces (accessed on 20 March 2020).

12. Csoma, H.; Zakany, N.; Capece, A.; Romano, P.; Sipiczki, M. Biological diversity of Saccharomyces yeasts of spontaneously fermenting wines in four wine regions: Comparative genotypic and phenotypic analysis. Int. J. Food Microbiol. 2010, 140, 239-248. [CrossRef] [PubMed]

13. Bramley, R.G.V. Precision Viticulture: Managing vineyard variability for improved quality outcomes. In Managing Wine Quality; Woodhead Publishing Series in Food Science, Technology and Nutrition; Reynolds, A.G., Ed.; 2010; pp. 445-480. Available online: https:/www.sciencedirect.com/book/9781845694845/ managing-wine-quality\#book-info (accessed on 20 March 2020).

14. Vigentini, I.; Maghradze, D.; Petrozziello, M.; Bonello, F.; Mezzapelle, V.; Valdetara, F.; Failla, O.; Foschino, R. Indigenous Georgian Wine-Associated Yeasts and Grape Cultivars to Edit the Wine Quality in a Precision Oenology Perspective. Front. Microbiol. 2016, 7, 352. [CrossRef] 
15. Cravero, M.C. Organic and biodynamic wines quality and characteristics: A review. Food Chem. 2019, 295, 334-340. [CrossRef]

16. Galati, A.; Schifani, G.; Crescimanno, M.; Migliore, G. "Natural wine" consumers and interest in label information: An analysis of willingness to pay in a new Italian wine market segment. J. Clean. Prod. 2019, 227, 405-413. [CrossRef]

17. Migliore, G.; Schifani, G.; Romeo, P.; Hashem, S.; Cembalo, L. Are farmers in alternative food networks social entrepreneurs? Evidence from a behavioral approach. J. Agric. Environ. Ethic 2015, 28, 885-902. [CrossRef]

18. Schimmenti, E.; Migliore, G.; Di Franco, C.P.; Borsellino, V.; Di Franco, P.C. Is there sustainable entrepreneurship in the wine industry? Exploring Sicilian wineries participating in the SOStain program. Wine Econ. Policy 2016, 5, 14-23. [CrossRef]

19. Pretorius, I.; Van Der Westhuizen, T.; Augustyn, O. Yeast biodiversity in vineyards and wineries and its importance to the South African wine industry. South Afr. J. Enol. Vitic. 1999, 20, 61-74. [CrossRef]

20. OIV- International Organization of Vine and Wine, 2017, Monograph of Saccharomyces Yeasts. Available online: http://www.oiv.int/it/norme-e-documenti-tecnici/le-risoluzioni-delloiv/risoluzioni-oenologia (accessed on 20 March 2020).

21. Resolution OIV-OENO 370-2012. Guidelines for the Characterization of Wine Yeasts of the Genus Saccharomyces Isolated from Vitivinicultural Environments. Available online: http://www.oiv.int/public/ medias/1429/oiv-oeno-370-2012-en.pdf (accessed on 20 March 2020).

22. Romano, P.; Pietrafesa, R.; Romaniello, R.; Zambuto, M.; Calabretti, A.; Capece, A. Impact of yeast starter formulations on the production of volatile compounds during wine fermentation. Yeast 2014, 32, 245-256. [CrossRef] [PubMed]

23. Available online: https://www.chr-hansen.com/en/about-us/history (accessed on 20 March 2020).

24. Padilla, B.; Gil, J.V.; Manzanares, P. Past and Future of Non-Saccharomyces Yeasts: From Spoilage Microorganisms to Biotechnological Tools for Improving Wine Aroma Complexity. Front. Microbiol. 2016, 7, 411. [CrossRef] [PubMed] 